\title{
Psychopharmacological Treatment in Athletes
}

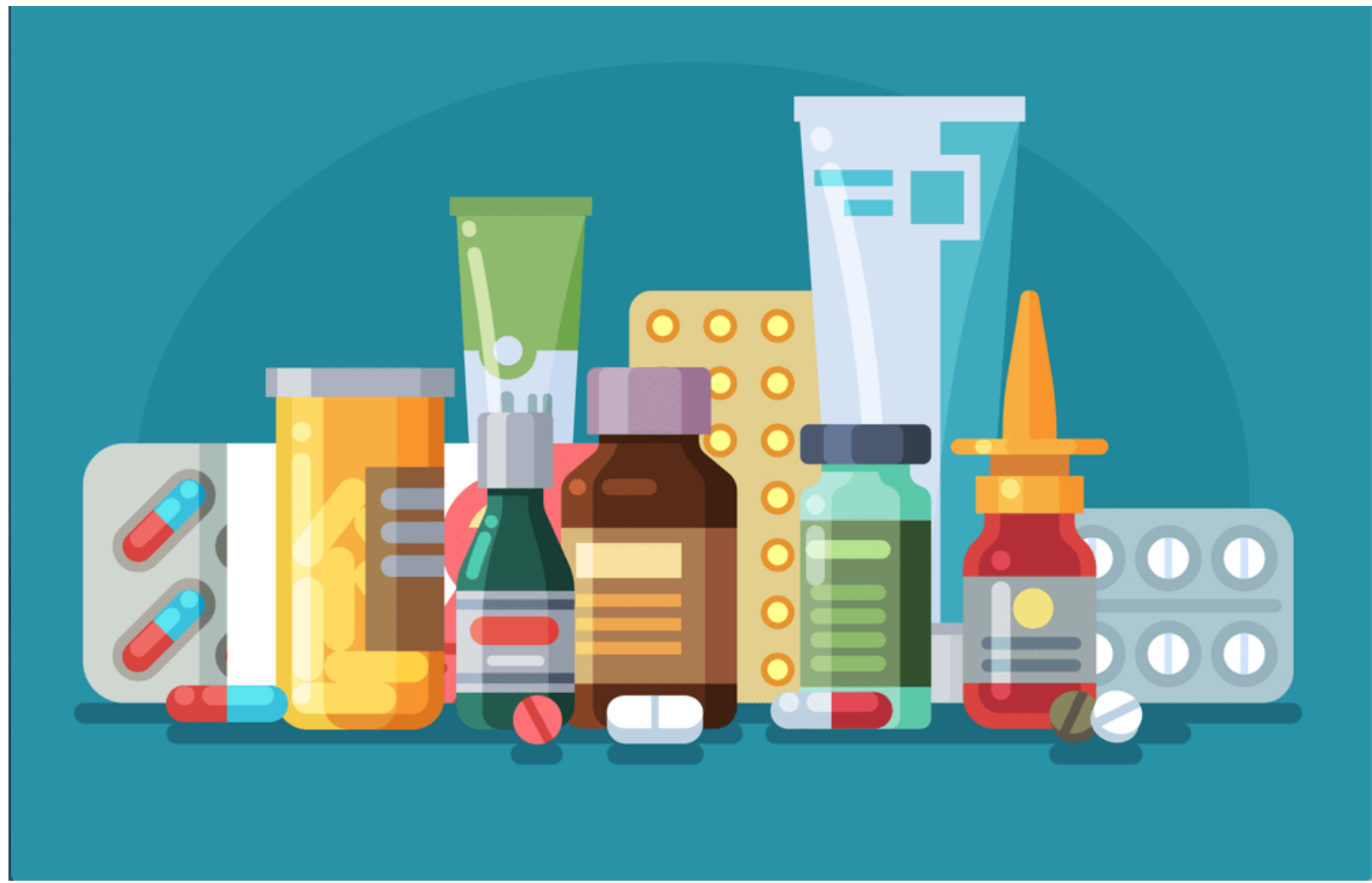

Berg Xaver $^{1}$, Colla Michael ${ }^{1}$, Vetter Stefan ${ }^{1}$, Seifritz Erich $^{1}$, Claussen Malte Christian ${ }^{1,2,3}$

${ }^{1}$ Department of Psychiatry, Psychotherapy and Psychosomatics, University Hospital of Psychiatry Zurich, Zurich, Switzerland

${ }^{2}$ Private Clinic Wyss AG, Münchenbuchsee, Switzerland

${ }^{3}$ Psychiatric Services Grisons, Chur, Switzerland

Pharmacological interventions play a substantial role in the treatment of psychological complaints.

However, while psychosocial and psychotherapeutic strategies are preferred for the treatment of mild to moderately severe symptoms, the use of drugs is often indicated for severe clinical manifestations [1,2]. In the general population, favorable and adverse effects of drugs are well established, specific studies regarding the effects of pharmaceutics on athletes are rare, and the few existing suffer from methodological flaws: Small sample sizes, predominant male participants, lower used dosages than in non- 
trial-setting or lack of psychiatric diagnoses in the study population [3]. Besides, in the care of athletes, the level of physical performance has to be considered, which should neither be impaired by used medication (e.g., through sedation, weight gain or disbalance), nor be artificially enhanced (e.g., through "ergogenic effects") to avoid distortion of competition [4]. Depression, anxiety, sleep disturbances, and ADHD are common psychiatric conditions in athletes [1]. In the following, often used pharmaceutical options of intervention shall be discussed regarding their potential side effects, effects on performance, and preference of sports psychiatrists [5]. Table 1 is supposed to give a rough overview of the substances described in the literature, and it does not claim completeness.

\begin{tabular}{|c|c|c|c|c|}
\hline Indication & Medication & Adverse Side Effects & Effect on Performance & WADA regulations \\
\hline \multirow[t]{2}{*}{ Depression } & $\begin{array}{l}\text { Fluoxetine } \\
\text { Paroxetine } \\
\text { (Reboxetine)* }\end{array}$ & $\begin{array}{l}\text { i. a. agitation, indigestion, sex. } \\
\text { dysfunction (men], dizziness, } \\
\text { low sex drive }\end{array}$ & $\begin{array}{l}\text { None } \\
\text { Impairment } \\
\text { Impairment }\end{array}$ & $\begin{array}{l}\text { None } \\
\text { None } \\
\text { None }\end{array}$ \\
\hline & Bupropion & i. a. less sensation of heat & Potential ergogenic & MP \\
\hline Anxiety disorders & Escitalopram & $\begin{array}{l}\text { i. a. agitation, indigestion, sex. } \\
\text { dysfunction [men] }\end{array}$ & Not studied & None \\
\hline \multirow[t]{3}{*}{ Sleep disturbances } & Melatonin & $\begin{array}{l}\text { i. a. headache, dizziness, indi- } \\
\text { gestion, elevated liver enzymes }\end{array}$ & None & None \\
\hline & BDZ & $\begin{array}{l}\text { i. a. drowsiness, muscle relaxa- } \\
\text { tion, misuse potential }\end{array}$ & $\begin{array}{l}\text { Impairment } \\
\text { [esp. longer half-lives] }\end{array}$ & None \\
\hline & Z Drugs & $\begin{array}{l}\text { i. a. dizziness, headache, } \\
\text { misuse potential }\end{array}$ & $\begin{array}{l}\text { Impairment } \\
\text { [esp. longer half-lives] }\end{array}$ & None \\
\hline Psychosis & $\begin{array}{l}\text { Aripiprazole } \\
\text { Lurasidone }\end{array}$ & $\begin{array}{l}\text { i. a. nausea, agitation, } \\
\text { weight gain } \\
\text { i. a. nausea, agitation }\end{array}$ & $\begin{array}{l}\text { Not studied } \\
\text { Not studied }\end{array}$ & $\begin{array}{l}\text { None } \\
\text { None }\end{array}$ \\
\hline Bipolar disorder & Lithium & $\begin{array}{l}\text { i. a. tremor, weight gain, } \\
\text { intoxication } \\
\text { i. a. dizziness, rash, HLH, } \\
\text { organ damage }\end{array}$ & $\begin{array}{l}\text { Not studied } \\
\text { Not studied }\end{array}$ & $\begin{array}{l}\text { None } \\
\text { None }\end{array}$ \\
\hline ADHD & $\begin{array}{l}\text { Stimulants } \\
\text { Atomoxetine } \\
\text { Bupropion }\end{array}$ & $\begin{array}{l}\text { i. a. agitation, elevated BP/HR, } \\
\text { less sensation of heat } \\
\text { i. a. elevated liver enzymes, sex- } \\
\text { ual dysfunction, nausea } \\
\text { i. a. less sensation of heat }\end{array}$ & $\begin{array}{l}\text { Ergogenic effect } \\
\text { Not studied } \\
\text { Pot. ergogenic }\end{array}$ & $\begin{array}{l}\text { Prohibited } \\
\text { in-competition } \\
\text { None }\end{array}$ \\
\hline
\end{tabular}

Table 1: Substances studied on athletes OR preferred by sports psychiatrists (excerpt). MP=monitoring program; BDZ=Benzodiazepines; HLH=hemophagocytic lymphohistiocytosis; BP=blood pressure; HR=heart rate; *not effective in antidepressive therapy. This table is a rough overview of substances and their effects in the care of athletes and does not claim completeness (for further information we recommend visiting http://www.compendium.ch)

\section{Antidepressants}

In the general population, SSRIs (e.g., Escitalopram) or Mirtazapine are considered effective and welltolerated drugs [6]. However, in the treatment of athletes, potential side effects like tremor or weight gain 
could lead to impaired performance [3]. Therefore, in a survey conducted on members of the international society of sports psychiatrists, Bupropion was the favorable substance used in the treatment of Depression without Anxiety [5]. As a remotely amphetamine-related substance, Bupropion is classified as an atypical antidepressant. It has a relatively unique profile of action (acting as a norepinephrine dopamine reuptake inhibitor and nicotine receptor antagonist) that does not typically cause weight gain or sedation. Because of a potential ergogenic effect, which can lead to enhanced performance, it is included in the 2020 Monitoring Program of WADA but is not prohibited in-competition. Bupropion was also shown to cause a suppressed sensation of heat, and it can lead to enhanced performance when taken before training in warm temperatures [7]. Therefore there are concerns that it can potentially increase the risk of developing heat illness. There are no studies regarding the effects of SNRIs on athletes, but Reboxetine was shown to impair physical performance [8] potentially. Paroxetine was also shown to potentially impair performance [9], which was the reason why Fluoxetine has been recommended to be taken into consideration, as it had no performance impairment [5,10,11].

\section{Anxiolytics/Sedatives}

Most sports psychiatrists seem to prefer Escitalopram for the treatment of anxiety disorders [5]. For sleep disturbances, there is a recommendation to use Melatonin over Benzodiazepines (BDZ) or Z Drugs. If the latter ones are used, one should prefer shorter half-lives over longer ones and Z Drugs over Benzodiazepines. BDZ can have muscle relaxant side effects, which could impair performance [4,12]. Long half-lives of BDZ can cause sedation the next day. Furthermore, both BDZ and Z Drugs have high abuse and dependency potential. Buspirone as anxiolytic was shown to have performance impairing effects and is therefore not recommended for the use in athletes [13].

\section{Mood stabilizers}

In the treatment of bipolar disorder or as an augmentation of antidepressive medication, Lithium is a powerful medical option [14]. Lithium has a narrow therapeutic range, and about performance-oriented sports activities, it should be considered that perspiration-related dehydration and reduced renal clearance could lead to toxic serum levels of Lithium [15]. However, there is evidence that in the case of sweating, lithium levels are reduced, which could lower the chance of acute intoxication [16,17]. Valproic acid could be an alternative to Lithium, but due to known teratogenic effects, it should not be prescribed to reproductive-aged women. Consequently, Lamotrigine seems to be the preferred option of sports psychiatrists in search of a mood stabilizer [5].

\section{Antipsychotics}

Psychotic disorders seem to be uncommon in athletes, although there is no reliable prevalence data. Common side effects of many antipsychotic medications are sedation and weight gain, both of which might impair athletic performance and are avoided by sports psychiatrists. There are no studies of antipsychotic medication in athletes, but because of the favorable spectrum of side effects, Aripiprazole or Lurasidone are recommended [5]. 


\section{Stimulants}

Stimulants are banned in-competition by WADA because of potential performance-enhancing effects. If used, the athlete needs to have a Therapeutic Use Exemption. There have also been concerns regarding the dangerous consequences of use, e.g. sudden cardiac death and heat illness [18]. To this date, no correlation of SCD and use of stimulants has been shown, but because of the suppressed heat sensation, heat illness could be promoted by stimulants, especially in warm environments [7,19,20]. There are no medication studies conducted on athletes with ADHD. Existing studies on healthy athletes are focused on short-lasting stimulants. Sports psychiatrists in general prefer Atomoxetine in the treatment of ADHD over stimulants, although it has known side effects like impotence or liver damage, and the onset of effect takes several weeks.

\section{Conclusion}

There is a lack of medication studies on the effects of psychiatric drugs on athletes. We think it is necessary to conduct those studies in order to provide the best possible treatment to athletes, especially when the existing substances of first-line treatment are prohibited by WADA, like in the case of stimulants.

\section{Corresponding author}

Dr. med. Xaver Berg

Department of Psychiatry,

Psychotherapy and Psychosomatics

University Hospital of Psychiatry Zurich,

Zurich, Switzerland

xaver.berg@pukzh.ch

\section{References}

1. Strohle A. Sports psychiatry: mental health and mental disorders in athletes and exercise treatment of mental disorders. Eur Arch Psychiatry Clin Neurosci. 2019;269(5):485-98.

2. WHO. Pharmacological treatment of mental disorders in primary health care. https://www.who.int/mental_health/management/psychotropic/en/2009. 68 p.

3. Reardon CL, Hainline B, Aron CM, Baron D, Baum AL, Bindra A, et al. Mental health in elite athletes: International Olympic Committee consensus statement (2019). British Journal of Sports Medicine. 2019;53(11):667.

4. Reardon CL. The sports psychiatrist and psychiatric medication. Int Rev Psychiatry. 2016;28(6):606-13.

5. Reardon CL, Creado S. Psychiatric medication preferences of sports psychiatrists. Phys Sportsmed. 2016;44(4):397-402.

6. Cipriani A, Furukawa TA, Salanti G, Chaimani A, Atkinson LZ, Ogawa Y, et al. Comparative efficacy and acceptability of 21 antidepressant drugs for the acute treatment of adults with major depressive disorder: a systematic review and network meta-analysis. Lancet. 2018;391(10128):1357-66.

7. Watson P, Hasegawa H, Roelands B, Piacentini MF, Looverie R, Meeusen R. Acute dopamine/noradrenaline reuptake inhibition enhances human exercise performance in warm, but not temperate conditions. J Physiol. 2005;565(Pt 3):873-83. 
8. Roelands B, Goekint M, Heyman E, Piacentini MF, Watson P, Hasegawa H, et al. Acute norepinephrine reuptake inhibition decreases performance in normal and high ambient temperature. J Appl Physiol (1985). 2008;105(1):206-12.

9. Wilson WM, Maughan RJ. Evidence for a possible role of 5-hydroxytryptamine in the genesis of fatigue in man: administration of paroxetine, a 5-HT reuptake inhibitor, reduces the capacity to perform prolonged exercise. Exp Physiol. 1992;77(6):921-4.

10. Parise G, Bosman MJ, Boecker DR, Barry MJ, Tarnopolsky MA. Selective serotonin reuptake inhibitors: Their effect on high-intensity exercise performance. Archives of Physical Medicine and Rehabilitation. 2001;82(7):867-71.

11. Meeusen R, Piacentini MF, Van Den Eynde S, Magnus L, De Meirleir K. Exercise Performance is not Influenced by a 5-HT Reuptake Inhibitor. Int J Sports Med. 2001;22(05):329-36.

12. Paul MA, Gray G, Kenny G, Pigeau RA. Impact of melatonin, zaleplon, zopiclone, and temazepam on psychomotor performance. Aviat Space Environ Med. 2003;74(12):1263-70.

13. Marvin G, Sharma A, Aston W, Field C, Kendall MJ, Jones DA. The effects of buspirone on perceived exertion and time to fatigue in man. Exp Physiol. 1997;82(6):1057-60.

14. Nelson JC, Baumann P, Delucchi K, Joffe R, Katona C. A systematic review and meta-analysis of lithium augmentation of tricyclic and second generation antidepressants in major depression. J Affect Disord. 2014;168:269-75.

15. Smith DF. The effect of exercise and pain-stress on the renal clearance of Lithium, sodium, potassium and creatinine in the rat. Int Pharmacopsychiatry. 1973;8(4):217-20.

16. Jefferson JW, Greist JH, Clagnaz PJ, Eischens RR, Marten WC, Evenson MA. Effect of strenuous exercise on serum lithium level in man. Am J Psychiatry. 1982;139(12):1593-5.

17. Miller EB, Pain RW, Skripal PJ. Sweat lithium in manic-depression. Br J Psychiatry. 133. England1978. p. 477-8.

18. Reardon CL, Factor RM. Considerations in the Use of Stimulants in Sport. Sports Med. 2016;46(5):611-7.

19. Liu H, Feng W, Zhang D. Association of ADHD medications with the risk of cardiovascular diseases: a meta-analysis. Eur Child Adolesc Psychiatry. 2019;28(10):1283-93.

20. Roelands B, Hasegawa H, Watson P, Piacentini MF, Buyse L, De Schutter G, et al. The effects of acute dopamine reuptake inhibition on performance. Med Sci Sports Exerc. 2008;40(5):879-85. 